\title{
Children's Understanding of Identity - The Kind of Referent That Children Have in Mind When Understanding Identity Arguments
}

\author{
Paul Weingartner ${ }^{1}$, Silvia Haring ${ }^{2}$ \\ ${ }^{1}$ Department of Philosophy, University of Salzburg, Salzburg, Austria \\ ${ }^{2}$ University Library, University of Salzburg, Salzburg, Austria
}

Email address:

paul.weingartner@sbg.ac.at (P. Weingartner), silvia.haring@sbg.ac.at (S. Haring)

\section{To cite this article:}

Paul Weingartner, Silvia Haring. Children's Understanding of Identity - The Kind of Referent That Children Have in Mind When Understanding Identity Arguments. Humanities and Social Sciences. Vol. 8, No. 2, 2020, pp. 51-62. doi: 10.11648/j.hss.20200802.12

Received: March 26, 2020; Accepted: May 12, 2020; Published: May 27, 2020

\begin{abstract}
In order to conduct the reader to several important features of the old concept of identity we use a dialogue between two brothers of age 14 and 10 (ch.2). These boys point to important problems for children's understanding identity. These are, for example, children's ability to use two different names for one object (referent) or how to understand that the same referent is described by different properties (morning/evening star problem) or how can the referent of a name (name of their grandmother) be identical with the referent of a description (woman living 2nd floor, door 13) etc. Such identity situations occur in the test with children described in ch.6. After some preliminaries concerning the used language (ch.3) we offer a classification of identity-statements (ch.4) since several forms of these are used in the identity test (ch.6). Chapter 5 is a detailed study of different types of referents which are used when children understand identity: thought-referent, discoursereferent, perspective-referent are the most important ones. The last - perspective-referent - has many ramifications because of the different types of "perspective". The last chapter describes an experimental test that has been done with 62 children of age between 3 and 4 years. The test included two identity stories accompanied by two preceding control stories. The result of the tests are as follows: 1. The correlation between age and the solution of the identity tasks is significant. 2. There is a significant difference between 3-years old and 4-years old children concerning both the identity tasks and that of the false belief task. 3 . There is a significant correlation between the solution of the identity tasks and the false belief task. Acknowledgement: We would like to thank Josef Perner for several valuable remarks.
\end{abstract}

Keywords: Identity, Reference, Classification of Identity-Statements, False-Belief-Task

\section{Introduction}

Identity is as old as philosophy and mathematics: there are questions connected with identity which seem trivial and others that seem difficult at first. On a closer look, however, most questions concerning identity turn out to be rather deep and complex problems. To show this is the task of the dialogue in ch. 2. That children at the age of $8 / 9$ years can understand most of the questions in the dialogue shows that they are able to discuss deep philosophical, psychological and linguistic problems.

After preliminaries on language in ch. 3 , we proceed to a classification of identity statements in ch. 4. Here, different types of identity statements are described and arguments are given in which they occur. It is specifically pointed out where the identity stories used in the tests fit into this classification. The purpose of ch. 5 is to split up the referent which is used when children understand identity statements. Although at least the first three kinds of referents (external referent, discourse referent, thought referent) are used in scientific literature, no definitions are to be found there. Therefore we propose definitions for those three and moreover for what a more complicated referent is - the so-called perspective referent - in definitions D4 and D5.

The last chapter is to describe the identity tests with children at age 3 and 4 . They show the interesting correlation that those children who are able to understand the so-called false belief task, also understand the given identity stories. 


\section{A Dialogue About Identity}

Mike: Flory, I need your help! You always have only the best grades in math. Today in the math lesson, we were taught the equations, but I am completely at a loss about it.

Flory: It isn't that difficult. What do you want to know?

M: I am at a loss about many things, for example, whether in an equation you say something about one thing or about two.

F: About two, since those two are compared or equated to one another.

M: But the teacher said something like "sub ...", but not submarine, I don't remember what it was.

F: Did he say "substitution" or "substitute"?

M: Yes, exactly, but I didn't get the meaning, do you know another word for it?

F: Instead of "substitute for" you can also say "replace by" or "mutual replacement".

$\mathrm{M}$ : Yes, he said in an equation you can always replace the left part by the right part and vice versa. That is why I am at a loss about it.

F: But look, this is very simple: Just exchange the left side by the right side or the other way round.

M: Yes, but if I did that with my homework in math or in the exam, I am sure I would get a fail.

F: Why do you think so?

M: Because then I could just write $y=y$ instead of $y=x^{2}-$ $2 \mathrm{x}$. In fact, this would be wonderful, since I'd have finished my math homework very quickly. And moreover, for such trivialities as $\mathrm{x}=\mathrm{x}$ or $3=3$, we need not go to school, which I dislike anyway. And then you are not right that an equation is about two things, but only about one thing.

F: I think now I know what you mean. And this question of yours is not so easy to answer.

M: There is another thing which seems quite strange to me.

$\mathrm{F}$ : What is it?

M: That the teacher claims, if an equation is valid, then the things on both sides are the same or they are identical. But this is not true!

F: Why not?

$\mathrm{M}$ : Because that on the left side is $\mathrm{y}$ and on the right side is $\mathrm{x}^{2}-2 \mathrm{x}$. And they are not the same.

$\mathrm{F}$ : This is the equation of a certain parapola. Let's take something simpler, for example $2 \times 3=6$ or $\sqrt{9}=3$.

M: Yes, okay, but different things stand on the left side and on the right side. To claim that both sides are the same sounds to me like saying "apple connected by a multiplication-sign with pear is identical with plum". It just isn't true that the things on the left side are the same as that on the right side.

F: I think I understand what you mean. What you have in mind is that the linguistic expressions (signs) that stand on the left side are not of the same form as those on the right side. This is certainly true. But nevertheless, we may use different signs (signs of different form) to refer to the same thing. For example, if you call me once Flory and then Flo.
M: But then, if it is the same anyway, why do we use different signs instead of using the same signs (or signs of the same form) - that would be much simpler. I mean, same signs for same things and different signs for different things.

F: Mike, you have in fact an important idea. This was proposed by a famous philosopher in a book using decimal classification. I don't remember the book or the author, we have to ask a philosopher [1] (5.53f. See section 4.1 below).

$\mathrm{M}$ : You see, my idea is great!

F: And it is also used by developmental psychologists who call it "mutual exclusivity" as our Mum told me. These psychologists claim that as young children $(\leq 4)$ we would not have been able to use two different names for one object. But this is not true, because I remember that we used "dad" and "father" and "daddy" very early and, as Mum says, at about 2.5 years. And a little later we used "punch" and "clown" for the punch in the Punch and Judy show.

M: But you know, if we use this idea, then we don't have any equations anymore and we need not learn them in school.

F: Perhaps this idea is not very practical or useful, like several ideas of philosophers. Imagine what the mathematicians would do without equations.

M: Yes, right. They would lose their jobs and we wouldn't have math lessons anymore. I would like that very much.

F: However, consider the following: We can say without difficulty that our granny $=$ our grandma $=$ Anna Elise Kainz $=$ the mother of our mother $=$ the lady residing at Glanstraße $16 \mathrm{D}, 2^{\text {nd }}$ floor, door 13.

Now you have several signs, different in form, which all refer to the same person. If you require same sign - same referent, different sign - different referent, you can only repeat the same sign "granny", "granny" ... four our granny.

M: But if that is as you say, then again, what the teacher said is false.

F: Why?

M: Because if I know that our grandma lives on the second floor, door 13, then I know more than if I only know that she is our grandma. Therefore what the left and the right side of the equation say is not the same. And now I don't mean that the signs on both sides are of different form, but that the things which they represent are completely different.

$\mathrm{F}$ : Yes. But this is the reason why such equations are informative in contradistinction to $\mathrm{x}=\mathrm{x}$ or $\mathrm{A}=\mathrm{A}$. I think this is what you mean.

M: However, that is why these equations are false, because they do not contain the same information on the left as on the right side.

F: On the one hand you are right, on the other you are wrong.

M: This is impossible, because this is a contradiction. Either I am right or else I am wrong.

F: You are right that the information given about our grandma on either side is different, but the person who is described by these different information units is the same.

M: But then these equations are at least sloppy and imprecise, attributes which the teacher uses only for us.

F: In what sense do you think they are sloppy? 
M: Because nobody tells us - not even the teacher - that the $=$ refers to the person grandma only, but not to the information that she lives on the second floor, door 13. How should we know to which things right or left the = refers to?

F: I think I know what you mean. There is a famous example from astronomy Mum explained to me: The morning star $=$ the evening star and both are the same as the planet Venus. It is due to a philosopher who was also a mathematician and whose name is something like Fregory or so.

M: But that's the same sloppiness as with grandma.

F: I have another example, which I like much more: It was in a theater performance (you were too young to join me then). There was a princess with a beautiful green robe. When she went out, another one came in with a beautiful orange robe. First I thought that the second was a different princess, but then I found out that both had the same face and same legs, everything else was covered by the robe. Then I remembered that in the theater they can change the color of the klieg light. And I observed that different spot-lights were on when the princess had a green robe and when she had an orange robe. So I concluded: the green princess $=$ the orange princess

M: But this still is not completely correct.

F: Why not?

M: Because being a green princess is not the same as being an orange princess. Just like being our grandma is not the same as being a woman living on the second floor, door 13 .

F: You really are in top form today. Your points are quite difficult.

M: I also want to tell my math teacher that being the square root of 9 is not the same as being the number 3 .

F: But if you calculate the square root of 9, the result is 3 . So you see it's the same.

M: However, before I do the calculation, I cannot know that the square root of 9 selects exactly the number 3 . Similarly, just from knowing that she is our granny, I cannot know that she lives on the second floor, door 13.

F: I think you are right concerning our grandma. Because a description does not always describe a unique object exactly. "Elderly woman living on the $2^{\text {nd }}$ floor" is not an unambiguous description like "young woman walking in the park with two dogs" does also not uniquely describe one person. There are several possibilities. On the other hand, square root of 9 is unambiguously the number 3 ; there are no other possibilities.

M: Too bad! It's a pity that I can't make this objection to the math teacher.

F: Imagine Mum's nice bike was stolen. And after the police found it, they put it into the lost and found office. Would you recognize it among other bikes?

M: It depends on whether there are several others of the same type and color.

F: Should we say that all bikes of the same type and color are the same or are identical, so that Mum could take any of them for her own?

M: No, Mum's is special.
F: Thus you see, identity in properties is not sufficient for identity of individuals. How could we find Mum's bike then?

M: Perhaps Mum's has a scratch in the color somewhere?

F: This is too imprecise. But these types of more expensive bikes usually have a number punched into the frame. Assume this number to be N. Then we could say, Mum's bike =the bike with the frame number $\mathrm{N}$.

M: Yes, that's a solution. But this last problem was also much easier than the questions I pointed out to you!

\section{Preliminary Remarks on Language}

In their paper on Mutual Exclusivity, Markman and Wachtel [2] claim (p. 124) that the first words of children are "labels of objects". The claim of Markman and Wachtel concerning Mutual Exclusivity has been strongly contested by Clark [3] who showed that very young children accept more than one term for an object. Her result has been put into a wider context by Doherty and Perner [4] by showing that childrens reluctance vanishes with the understanding of different perspectives in the false belief task. The authors refer to Rosch [5] for their claim. Linguistically, "labels of objects" are (a subclass of) noun phrases. Russell also thought that children's first words are noun phrases:

"There are words, however - including all those that a child learns first - that can be used in isolation: proper names, class-names of familiar kinds of animals, names of colors, and so on. These are what I call "object words" ... They have various peculiarities. First: their meaning is learnt (or can be learnt) by confrontation with objects ... Second: they do not presuppose other words [6] (p.25f.)."

Many investigations on the cognitive development of children are based on this claim and understanding, which explains their focus on noun phrases. However, the claim does not seem to be universally true. It seems that it is true for the "developed western world". But it is known that children from the Far East with Chinese or Japanese as a mother tongue have more verb phrases (especially for activities) among their first hundred words [7].

We have to emphasize from the beginning that such a restriction to noun phrases also holds for the following study. The identity statements used in arguments which were tested with children describe identity relations between individuals which are linguistically represented by noun phrases. Properties can also be represented by noun phrases. Although we shall mention the identity of properties in our classification (see ch. 5 below), we do not report on experiments concerning such identity relations here.

Moreover, as indicated above, we do not deal with identity relations between activities which are linguistically represented by verbs, for example "suppose" and "assume" or other synonyms of this kind.

1) Concerning noun phrases which refer to individuals, one usually distinguishes between two types: proper names and definite descriptions. Russell gave a definition of proper names which is also widely accepted in linguistics: 
"We shall define 'proper names' as those terms which can only occur as subjects in propositions ... We shall further define 'individuals' or 'particulars' as the objects that can be named by proper names [8] (p.142)."

Kamp and Reyle [9] (p. 64 and 246) provide a construction rule for proper names.

Definite descriptions are such representations which designate exactly one (at least one and at most one) individual or exactly one class (set). Several different theories of descriptions exist; Russell's theory of descriptions [8] and [10] is still one of the most widely known and used [9] (p. 248). Russell distinguishes two types of descriptions: definite ones and indefinite ones.

i. Definite descriptions refer to one individual or to one class. For example: the author of Wallenstein, the author of Hamlet, the capital of France, Susie's mother (presupposing that 'Susie' is an unambiguous proper name in the present context). Definite Descriptions are expressed by the phrase "the so and so". And in an assertive sentence: "The so and so is such and such".

ii. Indefinite descriptions refer to a property or to a set of properties. For example: an inhabitant of Salzburg, a poor child, a beautiful doll, a Mozart memorial. Indefinite descriptions are expressed by the phrase "a so and so".

2) Concerning proper names and definite descriptions which are used in children's identity statements, we want to emphasize the following points: Proper names are understood as referring to real objects; in the tests mentioned at the end of this study, these are real human persons. In general, using such proper names in a context establishes a discourse referent [11], which has an external anchor [9].

For example, some people may have two proper names like Cicero and Tully. While Cicero = Cicero is trivial, Cicero = Tully is not, since "Cicero" was the name of the writer whereas "Tully" was the name of the Roman senator. In these examples, the named objects exist in space and time. However, there is an old dispute on whether numbers exist, even though they occur in equations such as $3=\sqrt{9}$. We cannot enter into a discussion on these problems here, but refer to [12], [8] as well as [13] I and VII. For the "world" of children, fairy tales are important. For children, the objects and figures of a fairy tale (like Little Red Riding Hood, Sleeping Beauty, Haensel and Gretel) exist relative to the context of the fairy tale, i.e. children interpret indicative sentences of the fairy tale in such a way as if the sentences said of themselves "it is so (it is the case) as I say it". This is the so-called "positive usage of language [14]." It is the normal usage in everyday language, in works of literature and scientific discourse. It is also presupposed by Tarski's truth condition (his biconditional) [15] (p. 121f.). In exceptional cases, such as in jokes and unserious talk, it can be violated.

The way Whitehead and Russell's theory [10] of proper names and variables handles these objects is problematic, since $x=x$ is always true, but presupposes the existence of $x$.
Thus Hamlet $=$ Hamlet or Little Red Riding Hood $=$ Little Red Riding Hood are false. According to Whitehead and Russell, such expressions have to be interpreted as descriptions, since: the so and so $=$ the so and so can be factually true or factually false. Thus the present president of the US = the present president of the US is true whereas the present king of France $=$ the present king of France is false.

Meinong has distinguished objects that exist from objects that do not exist and for both types of objects the law of identity holds. Zalta [16] developed a theory with two types of relation: referring to real objects and encoding to non-real objects (as they occur in literature or fairy tales).

\section{Classification of Identity Relations}

\subsection{Identity Between Individuals}

The linguistic expressions referring to individuals are proper names and definite descriptions. Accordingly, we may distinguish between three ways of representing identity relations: using two proper names, using one proper name and one definite description or using two definite descriptions.

a) Two proper names

Assume the family cat has two names: 'Struppi' and 'Brummi'. Then it holds: Struppi $=$ Brummi. A respective identity argument runs as follows:

1. Struppi's fur is shaggy

2. Struppi $=$ Brummi

3. Brummi's fur is shaggy

The logical structure is: $\mathrm{Fa}, \mathrm{a}=\mathrm{b}$; therefore: $\mathrm{Fb}$

Two problems arise here: First, how to introduce a new proper name and second, how to understand the synonymy of the identity premise. Karttunen [11] (p.366) offered a proposal to answer the first problem by giving rules for establishing a discourse referent: "... the appearance of an indefinite noun phrase establishes a discourse referent just in case it justifies the occurrence of a co-referential pronoun or a definite noun phrase later in the text."

For example: Bill did not see a cat. But there was the cat the family called

"Brummi". He saw this cat later. Here the second sentence establishes a discourse referent with the name "Brummi". This is a very simple case where a discourse referent is established. Karttunen discusses several more complicated cases. One important class of cases is concerned with two types of words, factive and non-factive verbs. Factive verbs like know, realize, produce, create, cause ... etc. usually establish a discourse referent, for example: Bill realized (did not realize) that he had made a mistake. Whereas non-factive verbs as believe, think, conjecture, say, claim or doubt generally do not: John doubts that Mary has a car.

The second problem is children's understanding of synonymy, i.e. to understand that two linguistic expressions of different form (shape) refer to one and the same individual. This is not trivial. The cognitive development of children understanding synonymy is estimated differently w. 
r. t. age. The representatives of the theses of Mutual Exclusivity defend that children will not accept a second name for an individual (object) for which they already know a name. In other words, children are supposed to accept only a one-to-one correspondence between names (or definite descriptions) and referents. Such a one-to-one correspondence between linguistic signs and objects of reference was proposed by Wittgenstein in his Tractatus [1]:

"Gleichheit des Gegenstandes drücke ich durch Gleichheit des Zeichens aus, und nicht mit Hilfe eines Gleichheitszeichens. Verschiedenheit der Gegenstände durch Verschiedenheit der Zeichen."

Such a view, however, is not suitable for handling mathematical equations. The underlying (unusual) interpretation of variables in Wittgenstein's section 5.53 has been discussed in [17], [18] and [19]. Markman and Wachtel [2] try to show with 6 different tests that children between 3 and 5 years accept the one-one correspondence (Mutual Exclusivity). But some of their tests seem to depend to a great degree on how the second name is introduced. However, we shall not engage in a discussion of these results or on critical views of other scholars about it here. In any case, experiments by [20], [3] and [21] show that synonymy is understood quite well from 4 years onwards. Moreover, there are studies which show a kind of precursory basis for understanding synonymy: to learn that one referent can have two different appearances. For example, one ball with two sides of different color can be recognized by children of 1,5-2 years of age. Probably, such an understanding originates when children see mother, father or other family members in different clothes or may later be deepened when children dress-up themselves.

b) A proper name and a definite description

This is also a kind of synonymy: one referent is denoted once by a proper name and once by a definite descriptive phrase. An example used in the test (described below) is as follows:

1. Julia is looking for the bakery (she needs three rolls).

2. The baker $=($ Julia's $)$ uncle Lukas.

3. Uncle Lukas wears glasses.

4. Mr. A wears glasses; Mr. B does not, Mr. C does not (this is shown by a picture of three men)

5. To whom should Julia go? (test question)

6. Hidden identity premise: $\mathrm{Mr}$. A = the man who wears glasses $=$ uncle Lukas

7. Julia should go to Mr. A.

In his book [6] (p. 42) Russell defends the view that most of the significations we use are in fact descriptions, even though several of them look like proper names. Thus, in the above example, "Lukas" looks like a proper noun, but to be a proper noun it is too indefinite, since there might be several persons with the name "Lukas". Therefore "the Lukas who is Julia's uncle" is in fact definite description, presupposing that "Julia" names a unique individual in the respective context.

c) Two definite descriptions

This is again another type of synonymy: one referent is denoted by two definite descriptions. Examples are: the morning star $=$ the evening star. The author of Hamlet $=$ the author of Julius Caesar the composer of "Kleine Nachtmusik" = the composer of the Jupiter-Symphony

An argument using an identity premise:

1. Mike and his friends are playing with the cat.

The cat is Mike's cat.

2. Now the cat is running away.

3. Who will chase after it?

Identity conjecture:

4. The one who chases after it $=$ the one who is its owner

\subsection{Identity Between Properties}

As between individuals, one can also distinguish three types of identities between properties. The two properties can be represented by two predicates, by one predicate and a definite or indefinite description or by two descriptions.

a) Two predicates

This type is a kind of synonymy where two different predicates (i.e. two predicate expressions of different shape) represent one and the same property. Many predicates (denoting properties) can be represented by their extensions; that is, by classes the elements of which are those individuals that have those properties in common. In this case, identity of properties means coincidence of classes: the class of farmers $=$ the class of peasants; the class of trolley buses $=$ the class of trolley coaches. For their test on synonymy (with children), Doherty and Perner [20] used the following pairs: $\mathrm{TV}=$ television, lorry $=$ truck, woman $=$ lady, coat $=$ jacket. For bilingual children one could also use the names of the first ten numbers in two different languages.

b) A predicate and a definite or an indefinite description

Examples for such cases are explicit definitions which also occur in everyday language: $\operatorname{man}=$ rational animal, circle $=$ the set of points equidistant from one point, calorie $=$ the amount of heat required to raise the temperature of one kilogram of water by $1^{\circ} \mathrm{C}$. Here, the right side of these definitions are definite descriptions. A case where an indefinite description is used runs as follows: a farmer = someone who cares for cows and grass and soil. Here the right side, the indefinite description, contains necessary conditions. Thus, some identity tests with children might focus on finding necessary conditions for several professions like carpenter, smith, mechanic ... etc.

c) Two descriptions

Identity holds here between two groups of properties. An example from the tradition is: rational animal = featherless biped animal. Or: rational animal =animal being able to laugh. The objects of classical mechanics can be characterized as objects which can be described unambiguously by position and momentum: object of Classical Mechanics = object describable by position and momentum. In the cases above, definite descriptions are used. This however is not always possible if the properties used are neither sufficient nor necessary. In that case, one can only use indefinite descriptions: a morning star $=$ a star which is well observable in the morning an evening star $=\mathrm{a}$ star which is well observable in the evening 
Concerning Frege's example [22] (p.39) it holds: the morning star $=$ the evening star $=$ Venus. But it does not hold: a morning $\operatorname{star}=$ an evening star, since the properties "observable in the morning" and "observable in the evening" are not identical. That is, one has to distinguish between "the morning star" and "the evening star" (definite description) on the one hand and "a morning star" (to be a morning star) and "an evening star" (to be an evening star) on the other. The first pair has one external referent (Venus) whereas this is not the case with the second pair: the property of being a morning star $\neq$ the property of being an evening star [23] (p. 332).

\section{The Kind of Referent that Children Have in Mind When Understanding Identity Arguments}

In this chapter, we try to analyze four possibilities of referents which children might have in mind when understanding identity statements and identity arguments. The noun phrases used by children refer to something in some way. In which way do they refer to something and which general properties do the referents possess? The four types to be presented are not understood as excluding each other. Each type may be connected to some components (conditions) of another type.

We begin with external referent and continue with thought referent, since we think that the latter is more basic than the discourse referent. Finally, we try to characterize the perspective referent.

\subsection{External Referent}

By an external referent we usually understand an individual referent, which is linguistically represented (denoted) by a proper name (recall the characterization of proper name by Russell [6]). However, a definite description which designates a unique object or individual is also suitable. If predicates or class terms like rabbit, car or peasant are used, then only one particular individual of such a class can be an external referent.

We propose the following definition:

D1 $x$ is an external referent (ER) of a noun phrase in the (linguistic) context of $l$ iff the following conditions are satisfied:

1) the noun phrase is either a proper name or a definite description of $x$ in $l$

2) $x$ is assumed to exist in reality

3) $x$ satisfies certain minimal conditions for solid bodies of Classical Physics

Remarks on definition D1

Condition (2) has to be interpreted in a wider sense. For an adult and for a child, the objects surrounding us like tables, chairs, books, brothers, sisters or parents exist in reality, more accurately in space and time; that is, they are external referents. This also holds if such objects are not observed but stored in memory. In a wider sense, condition (2) is concerned with individual figures of literary work and of children's fairy tales. Figures from novels (for adults) and figures in fairy tales (for children) may have external referents for them on the condition that the statements in novels and fairy tales are interpreted according to the "positive usage of language" (recall section 2 of ch. 3 above).

Condition (3) may seem awkward at first, but in our view, the hidden presuppositions pointed out by this condition should not be ignored or neglected. It concerns many objects of everyday life for both adults and children. And more importantly for our study, it concerns those individual objects which appear in tests of the cognitive development of children. These objects have roughly the following properties, which characterize them as solid bodies of Classical Physics (more restrictedly of Classical Mechanics): they do not change their form (shape) when moved around in (the restricted) space of our surroundings; that is, they do not change when children relocate or orient them differently, if they move them slowly or fast. Moreover, they do not change with time, i.e. they are re-identifiable through time (for a suitable length of time). Objects which have these properties are called "Galilei-invariant" (in physics).

Observe that the objects have to be solid bodies, since fluids or gases can hardly be used in tests for children's understanding of identity relations. The quality of reidentifiability through time can also be illustrated when objects undergo some limited changes; for example, photographs of their parents in their childhood may be shown to children in order to understand enduring personal identity.

\subsection{Thought Referent}

According to modern view [24] and [8], proper names and definite descriptions directly designate an individual:

"A name ... is a simple symbol, directly designating an individual which is its meaning ...[8](p. 174)."

The traditional view is more sophisticated. According to Aristotle [25] (16a), Augustine [26] or Thomas Aquinas [27] (I,84,2), but also according to philosophers of the $19^{\text {th }}$ and $20^{\text {th }}$ century, like Brentano [28] (p. 124f.) and Bunge [29], noun phrases can only refer to objects via mediation of a (mental) concept. Pure reference relations of the kind "sign object" are idealized abstractions and have to be relativized to conceptual thoughts of human interpreters who connect a sign with its object as an external referent.

When making such a connection, we assume in accordance with the above mentioned philosophers that the interpreter forms a kind of conceptual picture a thought referent of the object or of the external referent.

In investigations concerning the cognitive development of children, Perner, Rendl and Garnham [30] arrived at objects of thought from another perspective: they were looking for an explanation as to why children can manage different tasks like alternative naming, false belief, synonymy, counterfactual reasoning, false direction signs and different perspectives approximately at the same age (4 years); they conjectured that forming an object of thought and being able to connect the object of thought with the respective external 
referent might be the unifying factor w. $\mathrm{r}$. t. the different tasks. Doherty and Perner [31] characterized the object of thought by several conditions. Three important ones are as follows: re-identifiable through time, representable by a defining label and anchored in an external referent. Our definition D2 also contains these three conditions. Since the experimental tests concerning arguments which contain identity premises are restricted to the identity of individual human persons, we have restricted the objects of thought to individual objects in our definition. Moreover we use thought referent in contradistinction to external referent and discourse referent (defined below).

D2 $x$ is a thought referent (TR) of a noun phrase $n$ in the language (context) $l$ iff the following conditions (1)-(6) are satisfied:

1) the noun phrase (NP) $n$ is either a proper name or a description, the meaning (or partial meaning) of which is $\mathrm{X}$

2) there is a human person $A$ who understands (to a sufficient degree) the language (context) 1

3 ) $x$ is a conceptual idea (conceptual picture) formed by A, which is the meaning (or part of the meaning) of $n$

4) A assumes (believes) that there is an external (individual) referent (ER) $r$ of $n$ corresponding to $x$

5) A assumes (believes) that $x$ corresponds to $r$ in such a way that all essential properties of $r$ are contained in $x$

6) $x$ is re-identifiable through time in the sense that $n$ and $x$ are stored in the memory of $\mathrm{A}$ and $\mathrm{r}$ can be recalled via $\mathrm{n}$ and $\mathrm{x}$

If conditions (4) and (5) are satisfied, we say that the NP $n$ is anchored via the TR $x$ to the ER $r$. Condition (1) guarantees the label (the NP $n$ ) which represents the TR $x$ in the linguistic context $l$.

In a similar way as in D2, one could define thought referent for simple or complex predicates representing classes of individual referents. This is not done here, because the tests for children's understanding identity reported in chapter 7 below are concerned with individual human persons only.

We shall now discuss the question whether the noun phrases used in the identity stories (test-stories) described in ch.7 signify thought referents. First, we can see that condition (1) of D2 is fulfilled: the noun phrases used in the identity stories are either proper names (David, Julia, Maria, Lukas) or descriptions (David's teacher, David's aunt, Julia's uncle, the baker Julia needs, David's school ... etc.). That condition (2) is fulfilled to a sufficient degree for each child is manifest by the discourse between each child and the experimenter. In order to support fulfillment of condition (3), puppets and pictures as referents for the noun phrases are shown to children. If they succeed in the test, (3) must obtain; but even if they do not or only partially succeed, they will form some conceptual picture as the meaning (or part of the meaning) of the noun phrases. Further, we can assume that children anchor (conditions (4) and (5)) their thought referents. One reason for this is that the noun phrases used in the stories A1 and A2 like 'uncle', 'aunt', 'teacher', 'baker' or 'house' ... etc. are known to children of that age. A second reason is that they might have a living, real aunt, uncle ... and know a real baker or teacher (the latter may be the case via their siblings). Condition (6) is satisfied when children manage the control story and the control test. Summarizing, we can say that by passing or partially passing the identity tests and the control tests, children form thought referents in the sense of D2.

\subsection{Discourse Referent}

One type of discourse referent is introduced by Kamp and Reyle [9] (p. 61). They characterize a discourse referent (DR) as a linguistic expression (formal representative) of an individual signified by a subject term in a subject-predicate sentence (where the predicate is satisfied by the subject).

A different and more specific concept of DR is due to Karttunen [11]. It is different, because he does not see the DR as a linguistic entity but as an extra-linguistic entity established by a co-referential pronoun or a definite noun phrase occurring later in the text [11] (p. 366 and 383). It is specific, because not every true subject-predicate sentence establishes a DR signified by the subject-term: "In this paper we will try to find out under what circumstances discourse referents are established [11]." For example, "John realized that Mary has a car" and "Jim did not fail to find an answer" establish a DR (car, answer) whereas "John doubts that Mary has a car" and "Jim wants (believes, expects) to catch a fish" do not (car, fish). But "John did not realize that Mary had a car" also establishes a DR (car), even though the verb is negated. In the cases above, this depends on whether factive verbs (know, realize, regret, act, bring about) or non-factive verbs (believe, doubt, conjecture, assume, think, say, claim) are used. Several other complicated circumstances for establishing a DR have been discussed by Karttunen.

For our purpose it is more interesting to ask how discourse referents are introduced in children's understanding. For them, DRs may exist even in cases where they do not exist for adults, because of non-factive verbs or similar reasons. Thus, as Karttunen says:

"Although discourse referents ordinarily exist for the speaker, there is a class of 'world-creating' verbs, such as believe, that also establish referents of another kind [11] (p. 383)."

Children seem to establish DRs relatively easily and even without such "world creating" verbs. In pretend play for example, a small wooden block establishes the DR piece of chocolate and a girl's doll establishes the DR (her) baby and the girl herself constitutes the DR mother. Thus, the real existence as an external referent is not necessary as is also shown by children's understanding of fairy tales. Taking these considerations into account, we think that a DR has to be defined as a type of thought referent (TR). The TR is always present in situations described by Karttunen or even by Kamp, and even more by the examples given concerning children's understanding.

Therefore it seems reasonable to consider a conception of a "discourse referent" which meets the following desiderata:

1) It is not just a linguistic expression which can be 
substituted for a subject term of a linguistic context [9]. It also does not have to fulfill a number of specific conditions [11]; otherwise the in this way restricted discourse referent is hardly distinguishable from the external referent.

2) The "discourse" is not just a linguistic context, but it should also take into account the semantics in the sense that the meaning (extension and intension) as it is present in the thought referent is incorporated.

3) The "discourse" should be an authentic discourse between human persons which requires not only a speaker or writer but also an addressee or an audience. This means that there are at least partially common thought referents of the persons communicating.

Perner, Rendl and Garnham [30] also defend a more specific demarcation for a discourse referent, underlining a similar point as (2) above. As an attempt to incorporate the three desiderata above, we propose the following definition for an individual DR:

D3 $d$ is an individual discourse referent (DR) iff

1) $d$ is an individual thought referent

2) there are human persons who are involved in a discourse in language $l$

3) $d$ is common or partially common to all the persons involved in the discourse

D3 can be applied to the test stories described in ch. 7 below: In the identity stories A1 and A2 (used in test for children of 3 and 4 years of age), several discourse referents are established according to definition D3; condition (2) of D3 is fulfilled, since there is a real discourse taking place between one of the authors, Silvia Haring (as the experimenter), and each child who took part in the test. Conditions (1) and (3) are satisfied, because David and Julia represented by puppets establish a thought referent common to the child and the experimenter. Further, the noun phrases 'teacher', 'David's aunt', 'baker' and 'Julia's uncle' establish thought referents which are common to the child and the experimenter. This is also the case for the noun phrases 'bakery' and 'school'. By definition D3, i.e. by satisfying all three conditions of D3, it follows that the noun phrases in A1 and A2 which signify human persons or other objects (buildings, pencils, rolls) establish discourse referents.

\subsection{Perspective Referent}

\subsubsection{Perspective View}

Doherty and Perner [20] and Perner [21] have shown that children understand synonyms (two labels viz. two linguistic expressions of the same form or shape for one referent) relatively early. A sort of precursor for this kind of understanding was the two-color test: a ball painted in two different colors on its opposite sides. Children (of around 2 years of age) understood that one ball can have two forms of appearance (recall section 4.1 (a) above). This refutes two strong mutual exclusivity claims. On the other hand, alternative naming (AN) situations are not interpreted by children as two forms of appearance or two labels of the same referent. And this agrees with logic: two labels, one referent and two properties, one referent is different from two classes containing different (or partially different) referents viz. two properties, each of them common to a class of referents. Several scholars have proposed the "perspective view" as a unifying explanation of this. According to Clark [3], speakers choose a perspective when they are going to talk about something. Clark thinks that children are able to use different perspectives already at about 2 years. This, of course, does not imply that these children are aware that they have their own perspective. Perner [32] try to find a unifying explanation for the well-confirmed fact that children begin to manage the false belief (FB) test at the same age (at about 4 years) when they manage AN-tests. They also think that these tasks are tasks for solving problems of perspective. They define "perspective" in a wider sense as "a way something is represented in a representational medium. (p. 357)" In the following, we shall use reference point or reference frame. A perspective view is then "a way something is represented" from a certain point of view or relative to some reference frame (or reference point). We prefer the latter expression, since it seems more easily applicable to the different types of perspectives which we distinguish below.

\subsubsection{Different Types of Perspectives}

a) Spatial perspective

Example: Where is the tree? It is in front of the rock, relative to observer $\mathrm{O} 1$ and behind the rock relative to observer $\mathrm{O} 2$. $\mathrm{O} 1$ and $\mathrm{O} 2$ are two different reference frames (points). In this case, we have one referent such that the situation can be described by an identity statement using two definite descriptions: the tree that is in front of the rock relative to reference point $\mathrm{O} 1=$ the tree that is behind the rock relative to reference point $\mathrm{O} 2$

b) Temporal perspective

Temporal perspective is analogous to spatial perspective, if the spatial extension or movement runs only in one direction.

Example: Florian's birthday is after Mike's, relative to the calendar year as present; but it is before Mike's birthday relative to the ecclesiastical year as present. Also, here we have one referent (the event of Florian's birthday).

The respective identity statement runs as follows:

The birthday that is after Mike's birthday relative to the calendar year = the birthday that is before Mike's birthday relative to the ecclesiastical year

c) Property perspective

Examples: Aristotle was a teacher w. r. t. Alexander the Great and an inventor of scientific methodology w. r. t. his Prior and Posterior Analytics. Thus, the identity statement reads: the philosopher who was a teacher relative to reference point Alexander the Great $=$ the philosopher who was an inventor of scientific methodology relative to reference point Prior and Posterior Analytics.

The property perspective can also be applied to the two identity stories used in tests with children of 3 and 4 years of age (see ch. 7 below). 
Identity story A1: Mary is (David's) teacher relative to the reference frame school and she is (an) (David's) aunt relative to the reference frame consanguinity (sister of parent).

Identity story A2: Lukas is a baker (needed by Julia) relative to the reference point profession and he is (Julia's) uncle relative to the reference point consanguinity (brother of parent).

d) Sortal perspective

Sortal perspective concerns class-inclusion in the sense of logic and set theory.

It occurs in AN-tasks for children. The expression 'AN' ('alternative naming') is misleading, since from a logical point of view, the noun phrases are no proper names but predicates or indefinite descriptions representing properties which are common to a class of individuals like tree, cow, rabbit, animal ... etc. In this case, we do not have one (individual) referent but one class of individual referents. Children's refusing to identify different sortals with different labels or names is therefore logically very well justified. Classes which include each other or which are subordinated to each other correspond to different conceptual levels, whereas different labels or names are concerned with the same conceptual level. Class inclusion also requires understanding of generalization as "all A's are B's" (all rabbits are animals) which is not required for different labels for one referent. It further requires understanding of subordination of an individual under a species as in: this is a cow.

From these considerations it follows that the type of sortal perspective is more complicated than the types discussed so far $(\mathrm{a})-\mathrm{c}))$.

Examples: This (thing) is a cow relative to the reference frame species and it is an animal relative to the reference frame genus, where species is included (class inclusion) in genus. The individual cow which has the property of being a cow relative to the reference frame species $=$ the individual cow which has the property of being an animal relative to the reference frame genus.

This rose is a flower relative to the reference frame species, is a plant, is a living thing relative to more general frames of reference such that there is transitive class inclusion.

e) Cultural-educational perspective

On a sheet of paper, three figures were shown to American and Chinese children: a cow, a chicken and grass. The children were asked to make a circle around those two (of the three) which belong (fit) together. American children circled cow and chicken, Chinese children cow and grass. When asked why,

American children explained that both form a group falling under a common class (animals) whereas Chinese children explained that both form a group of dependency since grass is essential for a cow [7] (p. 140f.), [33]. We may concentrate on pairs and may say the pair cow-chicken fits together relative to the reference frame sortal, the pair cow-grass relative to the reference frame interdependence or necessary condition of life. There is no identity relation between the two pairs. Which pair is selected depends on the reference frame.

f) Indexical perspective

Examples: Take the noun phrases 'father', 'mother', 'uncle', 'I' $\ldots$ or the possessive pronouns 'my', 'your', 'her' ... etc. From the reference point Susie, the father is Andreas, from the reference point Michael, the father is Norbert. 'I' refers to the person relative to the reference point present speaker or present writer. 'My' refers to the thing (s) relative to the reference frame possessed by the present speaker; 'her' refers to that or those thing (s) $y$ relative to the reference frame possessed by that person who stand (s) in a relation of possession to $y$.

It can easily be seen that this kind of perspective is more complicated than the types (a)-(e). One important difference is that there is no unique individual referent seen from different points of view or described relative to different referent frames. Instead, there is more than one possible referent and the question which referent is meant depends on the existence of (an) other referent (s) having a certain relation $R$ to the one selected from the possible referents. The relation $R$ in the above examples is fatherhood, actually speaking, possession. It can be any relation suitable for selecting the respective referent among the possible referents for the noun phrase in question.

Definition of "perspective referent"

Since the last type (indexical perspective) is essentially different form the types a)-e), we need two definitions D4 and D5 to reflect this difference. In cases a)-e), the general structure is as follows: the noun phrase $n$ has one referent in context $l$. This one referent $x$ (called the perspective referent 1) has the property $F$ relative to reference frame RF1 and the property $G$ relative to reference frame

RF2. In case f), the general structure is the following:

The noun phrase $n$ has more than one possible referent $x_{l}$, $\begin{array}{llll}x_{2} & \ldots & x_{n}\end{array}$. The question whether $x_{i}$ is the respective referent depends on the existence of one (or more than one) other referent $(\mathrm{s}) y\left(y_{1}, y_{2} \ldots y_{n}\right)$ having a certain relation $R$ to $x_{i}$.

D4 $x$ is an individual perspective referent of a noun phrase $n$ in the language (context) $l$ iff

1) $\mathrm{x}$ is an individual thought referent of $\mathrm{n}$ in 1 (D2)

2) there are properties F, G and reference frames RF1 and $R F 2$, such that $x$ has property $F$ relative to reference frame RF1 and $x$ has property $G$ relative to reference frame RF2

3) conditions 4) and 5) of D2 are satisfied in the sense that the external (individual) referent $\mathrm{r}$ corresponding to $\mathrm{x}$ has also properties corresponding to $F$ and $G$ relative to RF1 and RF2.

4) F, G, RF1, RF2 are constant within language (context) 1 This definition is applicable to the types of perspective a) to e).

D5 $x$ is an individual perspective indexical referent of a noun phrase $n$ in the language (context) $l$ iff

1) $x$ is an individual thought referent of $n$ in 1

2) there is more than one possible referent $x_{1}, x_{2} \ldots x_{n}$ of $n$ of which one of them, $x_{i}$ is selected to be identical with 
$\mathrm{x}\left(\mathrm{x}_{\mathrm{i}}=\mathrm{x}\right)$ by the respective reference frame

3 ) there is one (or more than one) other referent $y\left(y_{1}\right.$, $\left.\mathrm{y}_{2} \ldots \mathrm{y}_{\mathrm{n}}\right)$ and a certain relation $\mathrm{R}$ such that $\mathrm{x}_{\mathrm{i}}$ is the selected referent $\mathrm{x}$ (viz. $\mathrm{x}_{\mathrm{i}}=\mathrm{x}$ ) iff $\mathrm{x}_{\mathrm{i}}$ has the relation $\mathrm{R}$ to $\mathrm{y}\left(\right.$ or to $\left.\mathrm{y}_{1}, \mathrm{y}_{2} \ldots \mathrm{y}_{\mathrm{n}}\right)$.

4) $R$ is constant within language (context) 1

\section{Identity Tests with Children of age 3 and 4}

\subsection{Description of Tests}

Several types of tests in connection with the so-called Alternative Naming Game show that children under 4 years have problems to use two discourse referents (in the sense of two definite descriptions) for one and the same referent. Perner, Rendl and Garnham [30] tried to investigate, whether these problems are also present when children use identity statements. To answer this question, an identity story was told to children of 3 and 4 years of age; in the end, they had to answer a respective test-question.

In the particular study of Silvia Haring [34] two identity stories A1 and A2 together with two control stories A1' and A2' have been used. The tests have been done with 62 children of between 3 and 4 years. In A1, a boy, David, is looking for his teacher; he has to return a pencil to her. There are three women for choice, one of them holding a bouquet in her hands. The children are told that David's teacher is his aunt Mary. Then they are asked the control-question: Who is David's teacher? After that, the children get the information that David's teacher is holding a bouquet in her hands and they are reminded that David is looking for his teacher. Then they are asked: Where should David go?

In order to answer the test-question of A1 correctly, children have to make the following inference:

1. David's teacher = David's aunt Mary

2. David's aunt Mary is holding a bouquet in her hands

3. David's teacher = the woman who is holding a bouquet in her hands

4. David is looking for the teacher (in the school house)

Therefore: David should look for the woman (in the school house) who is holding a bouquet in her hands.

In the control story A1', a boy named David is looking for his aunt Mary. There are three buildings for choice, one of them is yellow with a red roof. The children are told that David's aunt Mary is teaching at present. Then they are asked: What is David's aunt Mary doing (just now)? And they are informed that the school-house is yellow with a red roof. They are reminded that David is looking for his aunt Mary. Then they are asked: Where should David go?

In order to answer the test-question of the control story correctly, the children have to make the following inference:

1. David's aunt is teaching at present.

2. The school building is yellow with a red roof.

3. David's aunt is (happens to be) in the school building.

4. David is looking for his aunt Mary.

Therefore: David should go to the yellow building with the red roof.

The first purpose of the study was to find out from which age on children can make correct identity inference. There is an essential connection of this question to the question of understanding that two signs (names or descriptions) may refer to one and the same referent. This is so, because in identity statements, two proper names, a proper name and a definite description or two definite descriptions refer to the same referent (recall section 5.1 above). The test had to show whether the children are able to transmit an information which they got by one description of an object to a different description of the same object.

In the identity story A2, a girl, Julia, is looking for the baker in the bakery. She needs 3 rolls. The children are told that the baker is Julia's uncle Lukas. Then they are asked the control question 1: Who is the baker? There are three men for choice, one of them wearing glasses. The children are informed that uncle Lukas wears glasses. They are asked the control question 2: Where is Julia's uncle? And they are reminded that Julia is looking for the baker. Then they are asked the test-question: Where should Julia go?

In order to answer the test-question of A2 correctly, the children have to make the following inference:

1. the baker $=$ Julia's uncle Lukas

2. Julia's uncle Lukas wears glasses

3. the baker $=$ the man who wears glasses

4. Julia is looking for the baker in the bakery

Therefore: Julia should look for the man in the bakery who wears glasses.

In the control story A2', Julia is looking for her uncle Lukas. She wants to ask him something. Children are informed that Julia's uncle is just baking bread. Control question 1: What is Julia's uncle just doing? There are three houses for choice, one of them has a red and yellow roof. Children are informed that the bakery has a yellow and red roof. Control question 2: Where is the bakery? Children are reminded that Julia is looking for her uncle Lukas. Then they are asked the test-question: Where should Julia go?

In order to answer the control question A2' correctly, the children have to make the following inference:

1. Julia's uncle Lukas is just baking bread.

2. Uncle Lukas is in the bakery.

3. The bakery has a red and yellow roof.

4. Julia is looking for her uncle Lukas.

Therefore: Julia should go to the house with the red and yellow roof.

A second purpose of the study was to find out whether the so-called "false belief" task [35] can be managed at about the same age at which children understand identity arguments of the kind A1 and A2 (including the control stories A1' and A2'). And also, whether an increase of understanding identity goes together with an increase of managing the false belief task.

The situation in the false belief task can be described in the following way: Maxi interrupts his play with the ball in order to get a drink. He puts his ball into the blue wardrobe and leaves. Lena comes in, takes out Maxi's ball and puts it into 
the green drawer. Then she leaves for the playground. Control question 1: Where did Maxi put the ball? CQ 2: Where is the ball now? CQ3: Who has put it there? CQ4: Did Maxi see that? CQ5: Where did Maxi put the ball in the beginning? If children give a wrong answer to any of these questions, the story has to be repeated. If they answer all the control questions correctly, they are asked the test question: Where will Maxi look for his ball?

\subsection{Results}

In this experimental study on children's understanding identity, the following two questions have been investigated and answered:

1. Is there a significant connection between age and the number of solutions in the three tasks: A1 (A1'), A2 (A2') and false belief?

2. Is there a significant connection between the solution of the identity tasks and the false belief task?

Hypothesis 1 (referring to question 1) is spilt into to hypotheses $1 \mathrm{a}$ and $1 \mathrm{~b}$.

Hypothesis 1a: Age has a significant influence on the frequency (number) of solutions

on the three tasks. Hypothesis 1a has been confirmed in the following sense: the correlation between age and the solution of identity tasks and that between age and false belief task are significant. The correlation between age and the control task is positive, but not significant. Age has significant influence on the identity tasks also under consideration of the solution of the control task. On the other hand, the solution of the control task has no significant influence on the solution of the identity task.

Moreover, there is a significant influence of the false belief task on the solution of the identity tasks under consideration of age.

Hypothesis 1b: There is a significant difference between 3year-old children and 4-year-old children concerning both the solution of the identity tasks and that of the false belief task.

Hypothesis $1 \mathrm{~b}$ has been confirmed in the following sense:

The children were split into three groups of age:

group 1: 3-3.5 years, $\mathrm{n}=22$

group 2: $3.5-4$ years, $\mathrm{n}=22$

group 3: 4 years, $\mathrm{n}=18$

The following diagram shows the correlations:

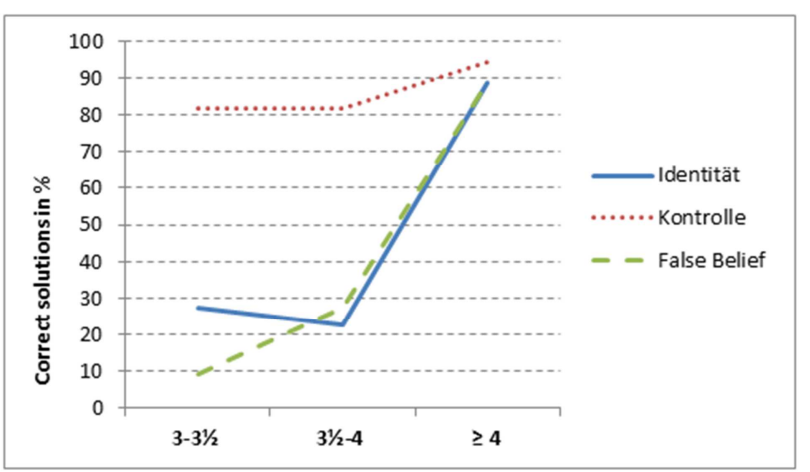

Figure 1. Correct solutions "Identity", "Control" and "False-Belief" subdivided into age group.
The diagram shows quite clearly that less than $30 \%$ of the children in group 1 and 2 were able to solve the identity tests in the correct way, whereas almost $90 \%$ of group 3 made correct solutions. Thus there is a significant difference between the three groups concerning the identity tasks. The control tasks A1' and A2' for the identity tasks have been answered correctly to a high degree by children of all three groups.

The frequency of solutions increases strongly for both the identity tasks and the false belief task above the age of 3.5 years. However, children under 3.5 years seem to have difficulties with both identity tasks and the false belief task. There is, therefore, also a significant difference between the three groups of age concerning the false belief task.

Hypothesis 2: There is a significant correlation between the solution of the identity tasks and the solution of the false belief task.

Hypothesis 2 has been confirmed by application of the Phi-correlation. The result is that the connection in group 1 is not significant, however it is significant for the age in group 2 and 3.

Effects of a sequential order or of parallelism of the tasks could be excluded as not significant.

\subsection{Conclusion}

The result of the study unambiguously shows that threeyear-old children have problems with understanding identity statements. For children under four years of age, it was difficult, if not impossible, to transform an information which they received by one description of a person to a different description of the same person.

The significant difference in the probability to find the right answer showed a further additional fact: the younger children not only had no appropriate understanding of identity, but even refused to refer two different descriptions to one and the same person. On the other hand, most of the four-year-old children had no difficulties to understand the respective identity inferences and to solve the identity tasks.

In order to exclude that younger children's difficulties in understanding identity inferences stem from problems with logical inferences in general, the respective control tests were invented. They were constructed in such a way that their content and structure was very similar to the identity stories; but to answer them correctly it was still necessary to manage a logical inference without identity premises.

From this it follows that the problems children have in understanding identity statements cannot be explained with problems they have with inferences in general; because the control tasks were managed with a high percentage also by younger children.

The frequency of solutions in the false belief tasks shows a similar pattern to that in the identity tasks (see diagram above). Both tasks were difficult for children with 3 years of age. There is a significant and positive connection between these two tasks. For further results concerning children's understanding of identity see [36]. 


\section{References}

[1] Wittgenstein, L. (1960): Tractatus Logico Philosophicus. In: Wittgenstein, Schriften I, Suhrkamp, Frankfurt.

[2] Markman, E. M. and Wachtel, G. F. (1988) Children's Use of Mutual Exclusivity to Constrain the Meaning of Words. Cognitive Psychology 20, 121-157.

[3] Clark, E. V. (1997): Conceptual perspective and lexical choice in acquisition. Cognition, 64 (1) 1-37.

[4] Doherty, M. J. and Perner, J. (2020): Mental files: Developmental Integration of dual naming and theory of mind. Developmental Review 56, 100909.

[5] Rosch, E. et al. (1976) Basic objects in natural categories. Cognitive Psychology 8, 382-439.

[6] Russell, B. (1940): An Inquiry into Meaning and Truth. Allen \& Unwin, London.

[7] Nisbett R. E. (2003): The Geography of Thought: How Asians and Westerners Think Differently and Why. Free Press, New York.

[8] Russell, B. (1919): Introduction to Mathematical Philosophy. George Allen \& Unwin, London.

[9] Kamp, H. and Reyle, U. (1993): From discourse to logic. Introduction to model theoretic semantics of natural language, formal logic and discourse representation theory. Dordrecht, Boston, London: Kluwer Academic Publishers. p. 64 and 246.

[10] Whitehead, A. N. and B. Russell (1927): Principia Mathematica. Universtiy Press, Cambridge. Ch.14.

[11] Karttunen, L. (1976): Discourse referents. In: J McCawley (Ed.): Notes from the linguistic underground. Syntax and Semantics, Vol. 7., Academic Press, New York. p. 363-385.

[12] Bernays, P. (1950): Mathematische Existenz und Widerspruchsfreiheit. In: Etudes de Philosophie des Sciences. Neuchatel, p. 11-25.

[13] Quine (1961): From a Logical Point of View. Harvard Univ. Press, Cambridge, Mass.

[14] Juhos, B. (1956): Der ,positive und der ,negative' Aussagengebrauch. Studium Generale 9, p. 78-85.

[15] Weingartner, P. (2000): Basic Questions on Truth. Kluwer (Springer), Dordrecht.

[16] Zalta, E. (1983): Abstract Objects: An Introduction to Axiomatic Metaphysics. D. Reidel Publishing Company, Dordrecht.

[17] Hintikka, J. (1956): Identity, Variables and Impredicative Definitions. Journal of Symbolic Logic 21, p. 225-245.

[18] Weingartner, P (1979): Scientific Understanding of a Text. In: Berghel H. et. al. (eds.): Wittgenstein, the Vienna Circle and Critical Rationalism. HPT Vienna, p. 183-190.
[19] Recanati, F. (2012): Mental Files, Oxford University Press. Part 4.

[20] Doherty, M. J. and Perner, J. (1998): Metalinguistic awareness and theory of mind: Just two words for the same thing? Cognitive Psychology, 13, 279-305.

[21] Perner, J., S. Stummer, M. Sprung and M. Doherty (2002): Theory of mind finds its Piagetion perspective: Why alternative naming comes with understanding belief. Cognitive Development, 17, 1451-1472.

[22] Frege, G. (1892): Sinn und Bedeutung. Zeitschrift f. Philosophie und philosophische Kritik, NF 100, p. 25-50.

[23] Weingartner, P. (1974): On the Characterization of Entities by Means of Individuals and Properties. Journal of Philosophical Logic 3, p. 323-336.

[24] Russell, B. (1905): On Denoting. Mind 14.

[25] Aristotle: De Interpretatione. In: The Complete Works of Aristotle. The Revised Oxford Translation, Vol. I, J. Barnes (ed.). Princeton, 1985.

[26] Augustine (DeM): De Magistro. In: Migne, Patrologia, series latina, Vol. 32, p. $1193-1222$.

[27] Aquinas, Thomas (STh): Summa Theologica. Transl. by Fathers of the English Dominian Province. Maryland, Christian Classics. Westminster 1981.

[28] Brentano, F. (1955): Psychologie vom empirischen Standpunkt, Vol. I, ed. O. Kraus, F. Meiner, Hamburg.

[29] Bunge, M. (1974): Semantics I. Sense and Reference. Reidel, Dordrecht.

[30] Perner, J., B. Rendl and A. Garnham (2007): Objects of Desire, Thought and Reality: Problems of Anchoring Discourse Referents in Development. Mind \& Language, 22 (5), p. 475-513.

[31] Doherty, M. J. and Perner, J. (2011): Mutual Exclusivity and Alternative Learning. To be published.

[32] Perner, J., J. L. Brandl and A. Garnham (2003): What is a perspective problem? Developmental issues in belief ascription and dual identity. Facta Philosophica, 5, p. 355-378.

[33] Wenzel, Ch. H. (2007): Chinese Language, Chinese Mind? In: Kanzian, Runggaldier (eds.): Cultures, Conflict-Analysis Dialogue. Proceedings of the 29. Intern. Wittgenstein Symposium. Ontos Verlag Frankfurt, p. 295-314.

[34] Haring, S. H. (2013) Probleme mit Identitätsaussagen im Kindergartenalter. Diplom-Thesis, Department of Psychology, University of Salzburg.

[35] Wimmer, H. and Perner J. (1983): Beliefs about beliefs: Representation and constraining function of wrong beliefs in young children's understanding of deception. Cognition, 13, p. 103-128.

[36] Huemer, M., Perner, J., Leahy, B. (2018): Mental files theory of mind: When do children consider agents acquainted with different object identities? Cognition 171, 122-129. 